\title{
Thermoelectric Exhaust Energy Recovery with Temperature Control through Heat Pipes
}

\author{
Jorge MARTINS, Francisco P. BRITO, L.M. GONCALVES, Joaquim ANTUNES \\ Universidade do Minho, Portugal
}

Copyright @ 2011 SAE International

\begin{abstract}
Currently, a great deal of the automotive industry's R\&D effort is focused on improving overall vehicle environmental and energy efficiency [1]. For instance, one of the things that Electric Vehicles (EVs) and Hybrid cars (HEV) have in common is the recovery of waste energy, namely during braking. But, when an I.C. engine is operating (e. g. as a range extender in an EV), a large amount of energy is also wasted within the exhaust gases and with engine cooling, energy that could otherwise be recovered by different methods. This paper reports on the recovery of waste thermal energy using thermoelectric generators (TEG) for application in hybrid, extended range electric vehicles and more generally in any vehicle that could benefit from the generation of a small amount of electric current that would reduce the alternator operation time.
\end{abstract}

Although some manufacturers are trying to develop TEGs to use at exhaust temperatures, there are still no commercially available TEG modules capable of withstanding these extreme temperatures. The present work assesses the potential of the use of heat pipes (HP) as a means of transferring energy from the hot exhaust gases to the TEG modules at a compatible temperature level while minimizing the loss of efficiency due to temperature downgrading. The type of HP used in this study is called Variable Conductance Heat Pipe (VCHP), and its deployment has the advantage of inducing good temperature control.

Various types of HPs were designed, manufactured, tested and improved with the aim of enhancing the overall heat transfer process, enabling an optimal level of electric energy recovery from the referred TEG modules. This was accomplished by the testing of different fluids inside the HP and by regulating the pressure of the gas chamber. Although the system is still under improvement, the results indicate that the use of VCHPs in conjunction with thermoelectric generators is a convincing technique for recovering otherwise wasted energy from the exhaust gases.

\section{INTRODUCTION}

The automotive world is on the verge of a major shift in paradigm, essaying a revival of the end of the 19th century, where electric vehicles were the rule rather than the exception. Full Electric and Extended Range Electric Vehicles (EREV, previously designated as Series Hybrid) are being made ready for customer acceptance, while Hybrids (HEV) have been sold by the million [2, 3].

\subsection{WASTE ENERGY REGENERATION}

Currently, the major automotive OEMs are investing a considerable portion of their R\&D budget on the so-called "Green technologies". Particularly, there seems to be a strong trend towards technologies that improve energy efficiency [1]. The hybridization of the vehicle is part of this shift in paradigm, in which thermal and mechanical energies being recovered into electricity take a major part. While a strong effort on the recovery of kinetic energy through regenerative braking is being made by most approaches [4], less attention has been put until recently on the recovery of waste thermal energy in the vehicle. In fact, the energy released through the exhaust of a vehicle, for instance, is of the same order of magnitude of the mechanical power supplied by the engine, although the former is not as readily usable as the latter $[5,6]$.

Page 1 of 19 
Several strategies should be implemented in order to improve engine efficiency [6] such as lean burn, supercharging and the use of over-expanded cycles. The latter subject was thoroughly studied by the authors [8]. The use of turbocompounds and turbochargers is also a way of recovering a portion of the exhaust gases' energy, although the deployment of such equipments may be problematic, especially for petrol engines $[5,6]$.

When an internal combustion engine is running at part load, the energy released by the fuel in the combustion is converted into useful work, directed to the cooling system and released in the form of exhaust gas enthalpy in, more or less, equal parts [5,6]. Therefore, the total power available at the exhaust and cooling systems (including water and oil) is roughly twice the mechanical power used for traction (Figure 1). Even if a small percentage of this waste energy could be regenerated into electric power and used to charge the battery pack of a Hybrid or EREV vehicle, or even be used solely to prevent the actuation of a conventional vehicle's alternator, the gains in efficiency for the vehicle could be important. The high temperature of the exhaust gases (up to $1000^{\circ} \mathrm{C}$ ) makes them potentially more apt for energy recovery than the lower temperature heat dissipated through the water cooling system of the vehicle. Nevertheless, these high temperature levels pose additional challenges that have not been easy to deal with until now [9].

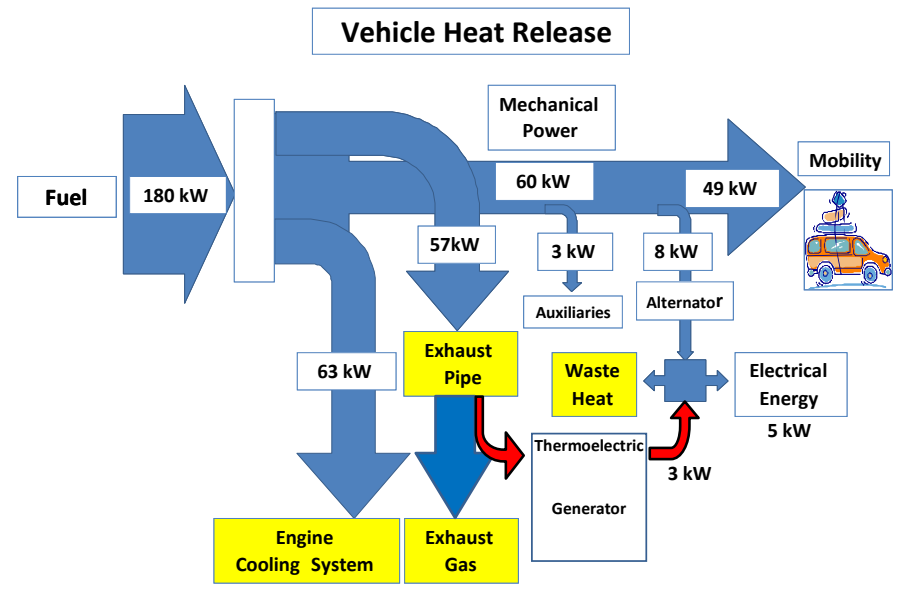

Figure 1 - Engine heat balance

\subsection{THERMOELECTRIC GENERATORS (TEGs)}

There are several ongoing studies focusing on thermoelectric recovery of waste exhaust heat, some rather recent and audacious, such as the use of Shape Memory Alloys (SMAs) to generate electricity [10] but this project is still on an early stage of development.

One way of regenerating exhaust waste heat that has been under development for some years is the use of thermoelectric generators (TEGs) based on the Seebeck effect (see Figure 2).

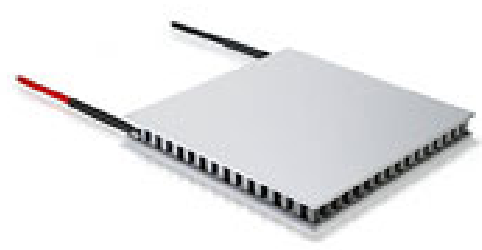

Figure 2 - Thermoelectric module

The Seebeck effect is also used for the thermocouple operation (but at a much higher scale), in which a temperature difference between the junctions of two different materials produces an electric voltage and an electric current flows when the electric circuit is closed. This effect is quantified by the Seebeck coefficient, $\alpha$, as represented in eq. 1 :

Page 2 of 19 


$$
\alpha=\frac{\Delta V}{\Delta T}
$$

A good thermoelectric generator device [11,12] should have a high Seebeck coefficient, and at the same time a low electrical resistance - Ri (thus allowing higher currents) and a low thermal conductance KP (thus reducing heat loss through the generator). The figure-of-merit (ZT) is used to quantify the performance of a thermoelectric module [10], or a single thermoelectric material, at a specific temperature $\mathrm{T}$ :

$$
Z T=\frac{\alpha^{2}}{R_{i} K_{P}} T=\frac{\alpha^{2}}{\rho k} T
$$

where $\alpha$ is the Seebeck coefficient, $\rho$ is the mean electric resistivity, $\mathrm{k}$ is the mean thermal conductivity and T the temperature (K). These coefficients are temperature dependent. Figure 3 shows the Seebeck coeficient (S), the electrical resistance (R) and the thermal conductance $(\mathrm{K})$ as function of the hot face temperature from a commercial thermoelectric module $(40 \mathrm{~mm} \times 40 \mathrm{~mm} \times 3.6 \mathrm{~mm}, 127$ junctions, $7 \mathrm{~A}, 15 \mathrm{~V})$ when the cold face is keep at constant temperature $\left(27^{\circ} \mathrm{C}\right)$. Despite the reduction of figure-of-merit $(\mathrm{ZT})$ with temperature, higher efficiency of the TEG is obtained when a high temperature difference is present between both faces of the module.

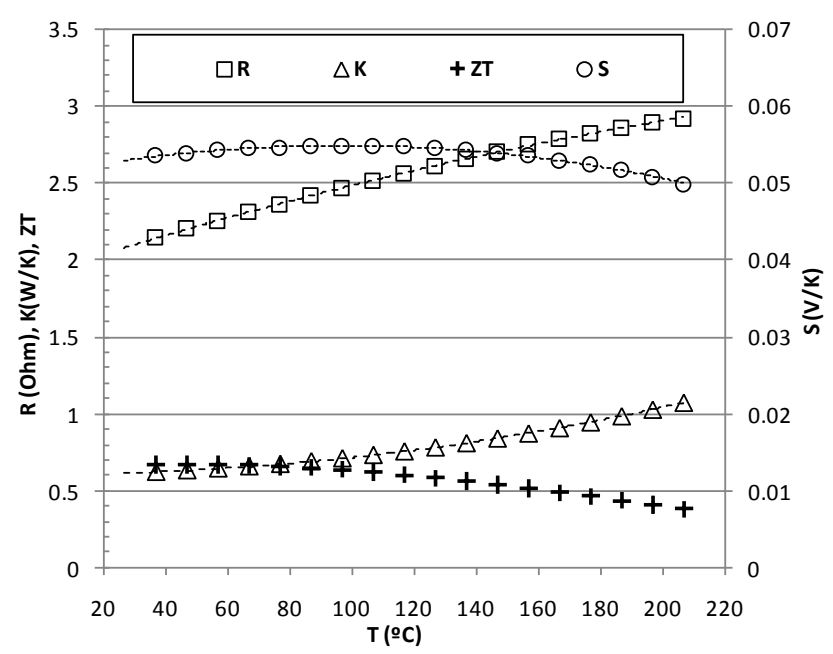

Figure 3 - Seebeck coefficient (S), electrical resistance $(R)$ and thermal conductance $(K)$ as function of the hot face temperature from a commercial thermoelectric module (cold face is at $27^{\circ} \mathrm{C}$ )

Figure 4 plots the output voltage, electrical power and efficiency of a thermoelectric generator, as function of hot side temperature, when the cold side is fixed at $27^{\circ} \mathrm{C}$. For temperatures above $230^{\circ} \mathrm{C}$, current TEG's are not suitable. High ZT thermoelectric materials for high temperature are still under development [13]. 

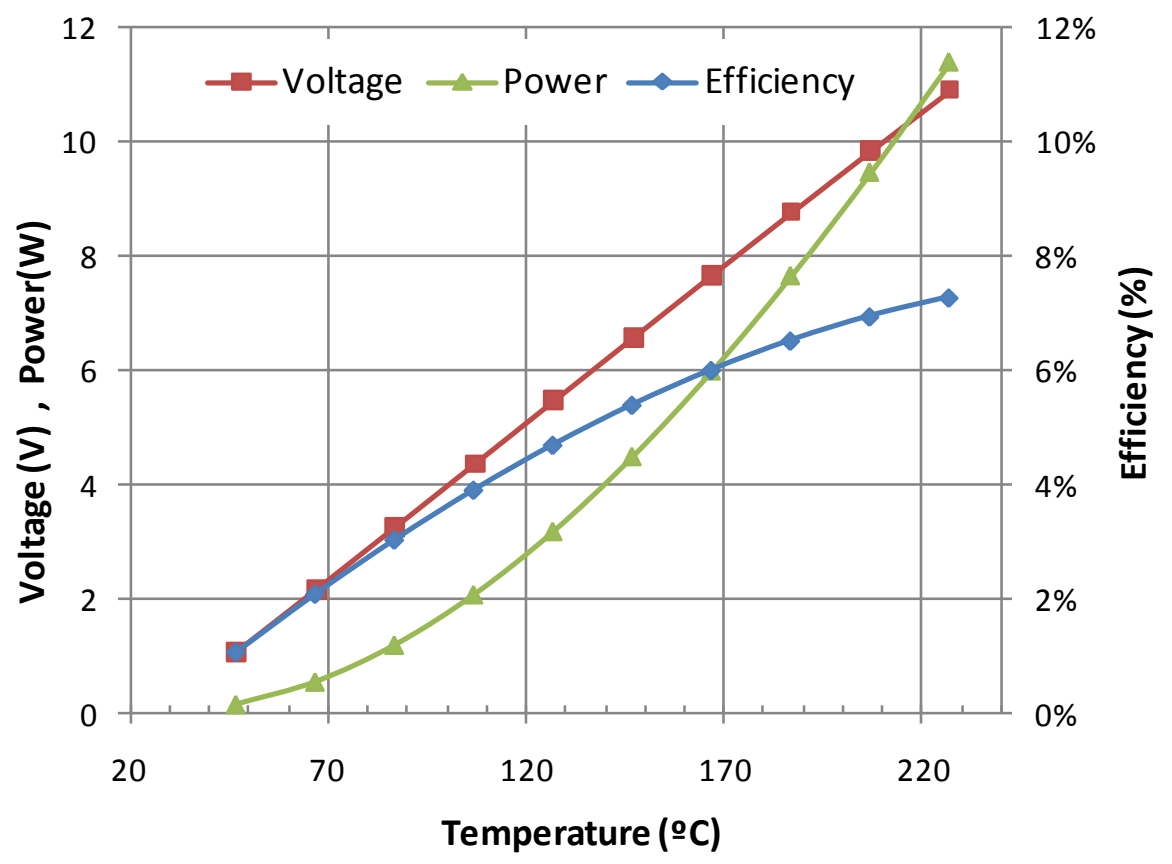

Figure 4 - Output voltage, electrical power and efficiency of a thermoelectric generator, as function of hot side temperature, (cold side is at $27^{\circ} \mathrm{C}$ )

\subsection{AUTOMOTIVE APPLICATION OF TEGS}

TEG technology was first tested in automotive waste heat recovery by Neild [14], followed by tests on modified cars/engines such as a Porsche 944 [15], a 14 litre Cummins Turbo-diesel engine truck [15,16] a GM Sierra Pickup Truck [17] and other, more recent works $[18,19,20,21]$, but in most cases the potential for power recovery is just enough to meet the electric demands of the various electrical accessories. However, reputable studies indicate that, if the system is properly designed, it should be possible to recover a significantly higher amount of energy [22, 23], when adding the combined potential of the cooling system, lubrication system and exhaust system. A major OEM (BMW) is testing this technology and is making plans to commercialize in the near future a car with TEGs generating up to $1 \mathrm{~kW}$ (currently $200 \mathrm{~W}$ ), with the aim of $5 \%$ fuel savings [24].

In fact, work such as Matsubara [25] refer an efficiency of heat recovery (to electricity) using advanced thermoelectric generators of $5 \%$, which would translate into an extra 6\% (1\% from coolant, 5\% from exhaust) of available (electric) energy in a hybrid car. Consequently, an engine with 33\% efficiency could earn 3\% extra mechanical power, translated into 5\% in fuel savings.

One of the reasons for the small thermal efficiency of TEG modules has to do with the limitations in the maximum temperature that current modules are able to withstand (normally, up to $230^{\circ} \mathrm{C}$ ). Rather than the core materials of the module, it is normally the solderings between parts that are currently limiting their ability to work at higher temperatures [11]. This is one of the main obstacles when trying to regenerate exhaust heat by using TEGs.

One rather crude way of protecting TEGs against the extreme temperatures found in exhaust systems would be to partially insulate them. This solution would be highly ineffective as only a small portion of the heat would be available for recovery, mainly at light loads. Some tried to minimize this problem with the help of several heat exchangers [15]. The ideal solution, however, would be to effectively control the maximum temperature at the modules without sacrificing the heat available for recovery, or, in other words, it would be to regulate the temperature reaching the modules to nearly their working limit [9]. This would be made, not by insulating them or deflecting the heat flux away from them but, by supplying the heat to a sufficiently low temperature while still maintaining a high heat transfer rate. As it will be shown in the present work (and also previous work by the group [9]), this can be achieved with the combined use of heat pipes (HP) and TEGs.

Page 4 of 19 


\subsection{USE OF HEAT PIPES FOR TEMPERATURE CONTROL}

\subsubsection{Working principle}

Although very simple in their working principle, HPs are of relatively recent use in industry [26]. Basically, a standard Heat Pipe consists of a sealed upright pipe containing a small portion of phase-changing fluid (typically water). The remainder of the inner volume of the pipe is occupied either by a mix of thermal fluid vapour and non-phase-changing gas (typically air) or solely by the former. Due to gravity, the fluid rests at the bottom of the pipe (the heat source region, or evaporator of the HP), where it will be heated and boiled under the action of the heat crossing the pipe walls through conduction. The vaporized fluid will eventually condense at the upper part of the pipe wall releasing its heat to the heat sink. Once condensed, the liquid droplets fall back to the bottom of the pipe, completing the cycle and being ready to vaporize and condense over and over again (see Figure 5).

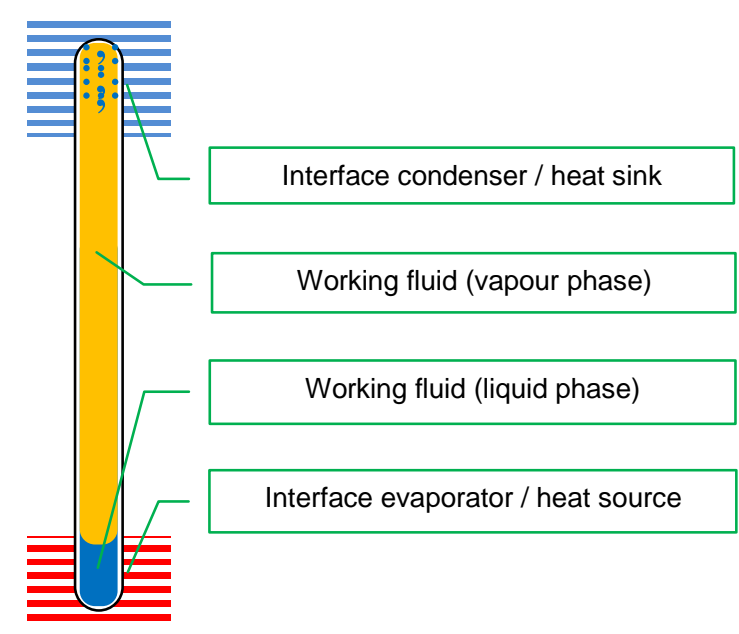

Figure 5 - Outline of a standard Heat Pipe

The heat transfer rate obtained through a typical HP is exceptionally high exactly because it is based on a phase change phenomenon, known for its intense heat transfer rates [27, 28]. This will be true as long as there is enough heat to achieve boiling conditions and not too much to initiate the Leidenfrost phenomenon [29], which consists on the formation of a film of vapour interposed between the HP walls and the liquid phase, that dramatically reduces heat transfer.

\subsubsection{HP operating temperature}

A Heat Pipe only starts transferring heat from the hot source to the heat sink once the boiling temperature of the fluid has been achieved. This boiling temperature is not a static value but it depends on the actual pressure of the vapour inside the HP (that also changes during operation).

There is a balance between the heat supplied to the evaporator, the heat removed from the condenser and the temperature-pressure equilibrium of the fluid inside it. Eventually, the working temperature of the HP (the boiling temperature) will stabilize. The main drawback of such system is when an excessive heat load increases the pressure (and the temperature) to dangerous levels.

\subsubsection{The influence of non-condensable gas inside a HP}

If a HP is sealed at ambient conditions, its void volume will be filled mostly with air. This air is at atmospheric pressure when at room temperature and prevents the boiling of the water below $100^{\circ} \mathrm{C}$. Another option is to remove the air with a vacuum pump prior to sealing the Heat Pipe. In this case, the starting boiling temperature will be much lower and therefore the HP will start transferring heat much earlier. On the other hand, the presence of air hampers the access of the vapour to the condenser area, therefore reducing heat transfer.

\section{Page 5 of 19}




\subsection{VARIABLE CONDUCTANCE HEAT PIPES (VCHPs)}

One way of controlling the phase changing temperature of a fluid would be to control its pressure. If the pressure could be kept constant at a specified value, then a certain HP operating temperature could be regulated. The use of a large volume tank attached to the top of the HP will enable this outcome. This way, pressure would not increase as it would in a standard HP and the boiling would not be hampered by an excessive increase of pressure.
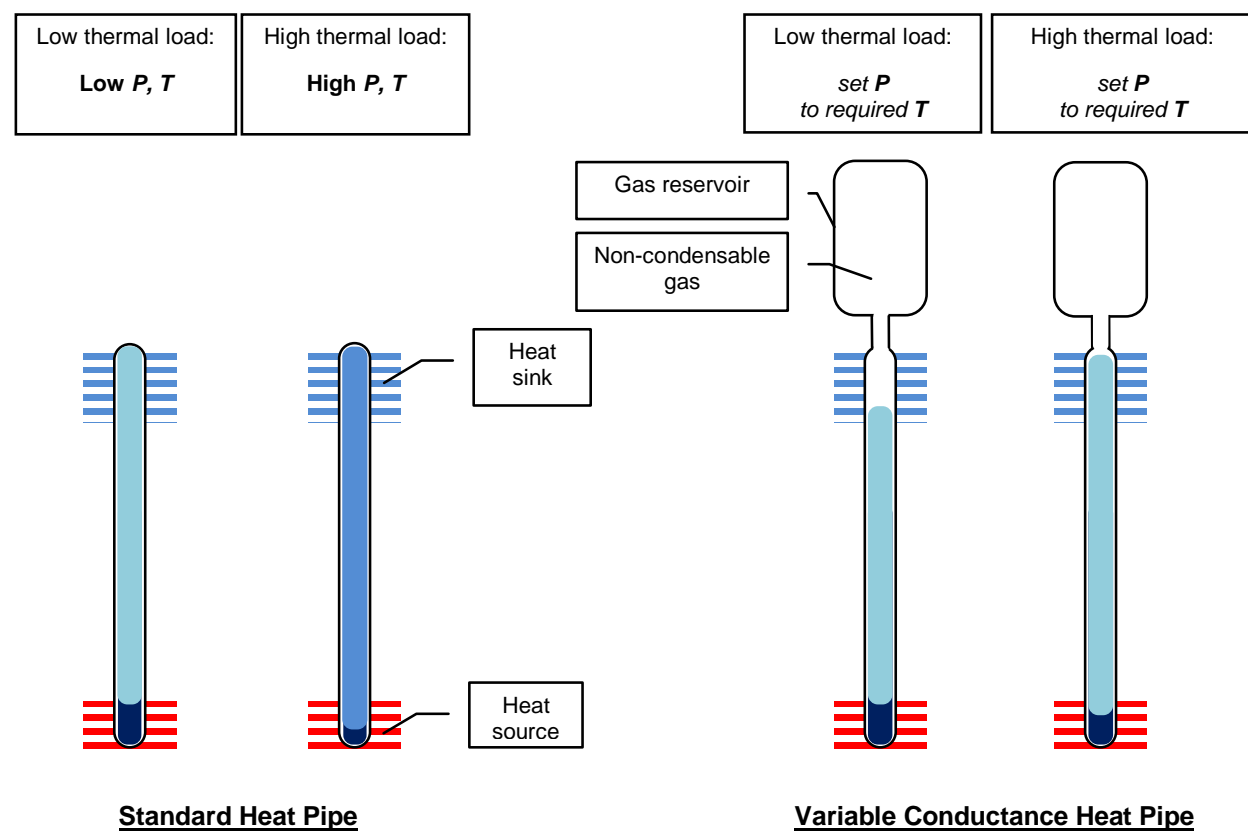

Figure 6 - Constant vs. Variable Conductance Heat Pipes

Figure 6 outlines a comparison between the response standard HPs and VCHPs for low and high thermal loads. It is expected that with this system the HP will be able to work at a specified temperature. This will be made by adjusting the HP pressure to control the boiling temperature (the operating temperature of the VCHP) regulating it to the maximum allowable TEG temperature, thus optimizing the heat transfer rate of the system.

\subsection{SCOPE OF THE PRESENT WORK: COMBINED USE OF HPs/VCHPs AND TEGs}

As discussed, the main limitation for the application of current TEGs to the exhaust system of vehicles is the temperature excess at the hot source (exhaust pipe). An easy way to use this heat at a lower temperature level with strong heat transfer rates is to use a VCHP with the evaporator embedded in the exhaust gases and with TEG modules connected to its evaporator. Additionally, a cooling water circuit retrieves heat from the opposite side of the modules extending the $\Delta \mathrm{T}$ across the modules.

The objective of the present work is, therefore, to assess the potential and optimize the design features of a heat transfer device (based on a VCHP) capable of efficiently transfer heat from hot exhaust gases to temperature limited TEG modules for electric generation in automotive applications. 


\section{EXPERIMENTAL PROCEDURE}

\subsection{PRELIMINARY TESTS}

Figure 7 shows the HP setup used in the first tests. A copper pipe ( $22 \mathrm{~mm}$ diameter, 200mm long) was soldered between a copper base plate and a copper top cylindrical container. The heat pipe volume was partially filled with a fixed amount of water (5 mL to $20 \mathrm{~mL}$ ) and air. A pressure ranging from 0.1 mbar (obtained with a rotary vacuum pump and further referred to as vacuum in the article) to 12.5 bar (using an air compressor) was set in the interior of the HP, during the various tests. The top cylindrical container was filled with $0.4 \mathrm{~L}$ of water, at room temperature $\left(25-30^{\circ} \mathrm{C}\right)$. Heat was transferred to the base using an electric hot plate. Three thermocouples were used for measuring the temperature of the base plate, of the inner vapour of the HP and of the water of the cylindrical container, respectively. A thermal grease was applied at this interface in order to enhance the heat transfer.

In each test, heat was transferred to the base plate, and temperatures were recorded each second, until the water in the cylindrical container reached the boiling point $\left(100^{\circ} \mathrm{C}\right)$. The temperature increase of the water in the top cylinder was used to measure the power transmitted through the $\mathrm{HP}$, considering the water mass $(400 \mathrm{~g})$ and its heat capacity $(4.2 \mathrm{~kJ} /(\mathrm{kg} . \mathrm{K})$.
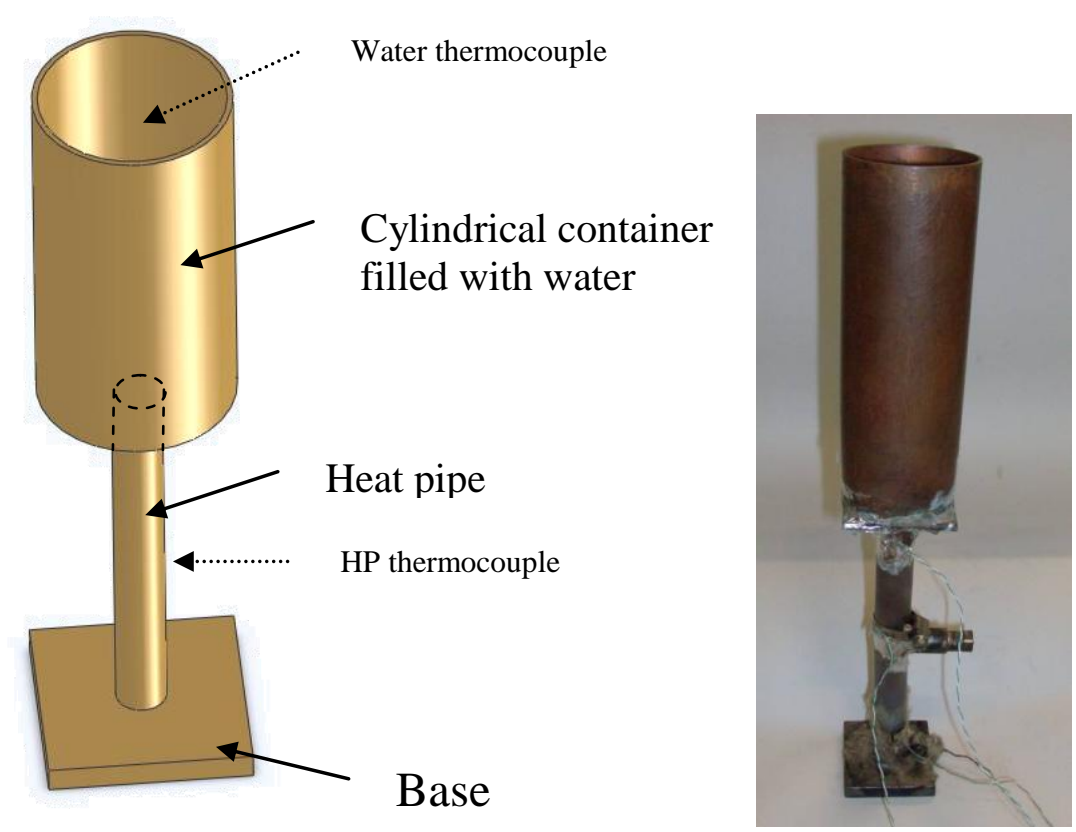

Figure 7 - Initial setup: Heat Pipe setup between a base plate and a cylinder filled with water.

\subsection{IMPROVED HP / VCHP SETUP}

In the second setup (Figure 8), the evaporator and condenser areas of the HP (respectively the contact area between the base and the water inside the HP and the contact between vapour and the cylindrical container) were substantially increased. Whereas in the initial configuration displayed in Figure 7 only the extremities of the HP were in contact with the heat source and the heat sink, in this new configuration the heat transfer areas are extended cylindrical surfaces. At the condenser region the pipe was extended well into the cylindrical container. For the HP base this was achieved by using a solid brass rod with a drilled hole, in which the tip of the HP was inserted and soldered. The lengths of the HP evaporator and condenser regions were extended to $50 \mathrm{~mm}$ and $60 \mathrm{~mm}$, respectively. The total HP length was $200 \mathrm{~mm}$, as in the previous setup. Moreover, an external connection (see Figure 8c) was added at the top end of the HP, in order to enable the addition of a $20 \mathrm{~L}$ closed cylinder tank, for pressure control of the HP. The same three thermocouples were used: base temperature, vapour temperature inside HP and water temperature. Several thermocouples were also placed along the pipe connecting the HP and the closed tank in order to evaluate to what extent the vapour has expanded out of the HP and into the pipe/cylinder region. If an increase of temperature along this pipe occurs it will mean that the vapour inside the HP has expanded sufficiently to reach this pipe or even the cylinder itself. This setup was used first without the closed tank and subsequently with it.

Page 7 of 19 


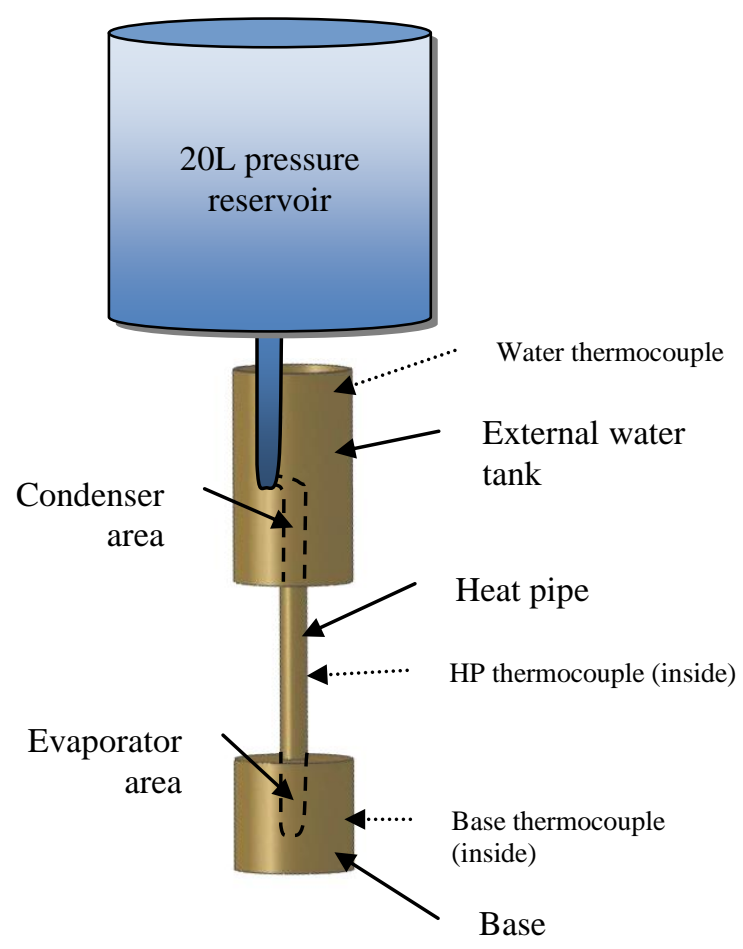

(a)
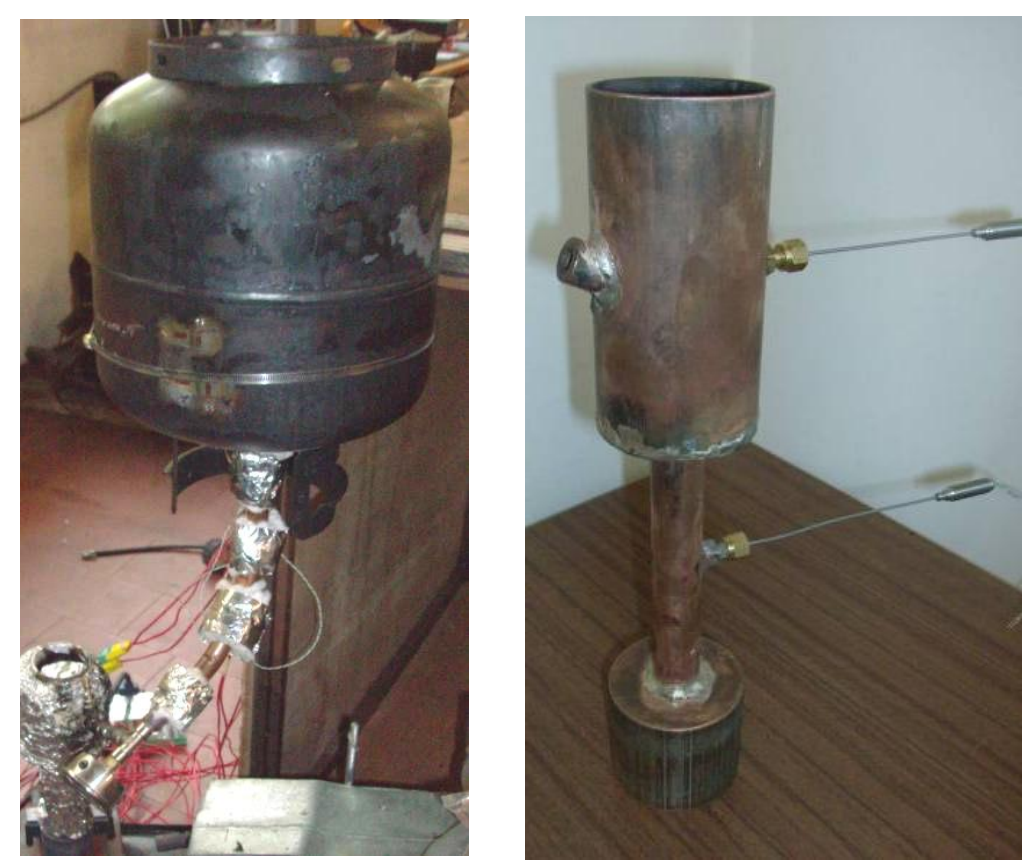

(b) (c)

Figure 8 - (a) Outline and (b) photograph of the improved Heat Pipe setup, with optional 20 L cylinder tank for VCHP operation. (c) Detail of the bare HP without the tank attached.

One/two blow torches that burned propane directly on the cylindrical base of the HP were applied (Figure 9). The maximum flame temperatures were around $800^{\circ} \mathrm{C}$ and $1000^{\circ} \mathrm{C}$ for one and two blow torches, respectively. These temperatures are comparable to those found in automotive exhaust systems (typically $700^{\circ} \mathrm{C}$ ). The cylindrical base of the HP zone has a thick wall of brass in order to protect the tube and produce some damping of the heat transferred to the HP.

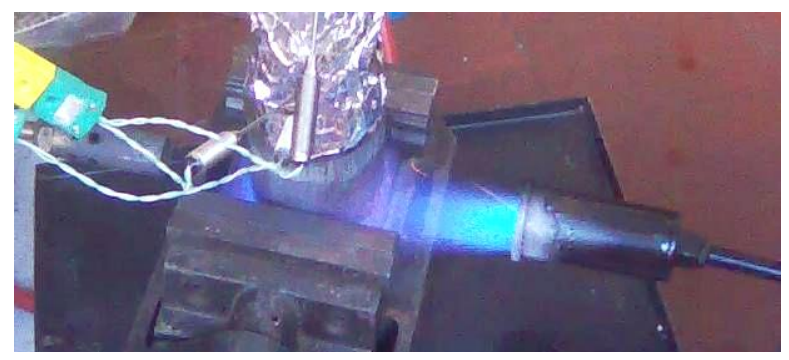

Figure 9 - Heating of the HP by 2 blow torches

With the setups of Figure 7 and Figure 8, the tests were carried out only until the moment where the cylinder water temperature reached $100^{\circ} \mathrm{C}$. At this temperature, the water in the cylinder would start boiling and power transmitted by the HP could no longer be calculated. In these designs no thermoelectric modules for electric energy generation were added. 


\subsection{SOLID TOP VCHP PREPARED FOR TEG INCORPORATION AND COOLING}

The last design was built to allow the attachment of TEG modules. Instead of the cylindrical water container, a solid brass block was added at the condenser region (see Figure 10) This block has a drilled hole acting as the condenser region, to which the tip of the pipe has been soldered. Four thermoelectric modules were attached to two of the faces of the block, while two water ducts were used to cool the outer surface of the modules, as seen in Figure 10a). The heat is transmitted from the vapour to the copper block, and from there to the cooling water, across the TEG modules. A water flow from 40 to $115 \mathrm{~L} / \mathrm{s}$ was imposed. The $20 \mathrm{~L}$ cylinder tank was used for all the tests using this configuration. 4 High-temperature thermoelectric modules were used. The model was the TEC1-12707 from Thermoelectric Supplier. They have 127 pairs of junctions, in a $40 \mathrm{~mm}$ x $40 \mathrm{~mm}$ x $3.9 \mathrm{~mm}$ package and can withstand temperatures up to $238^{\circ} \mathrm{C}$. Some tests were made prior to TEG attachment just to evaluate the heat transfer potential of the system.
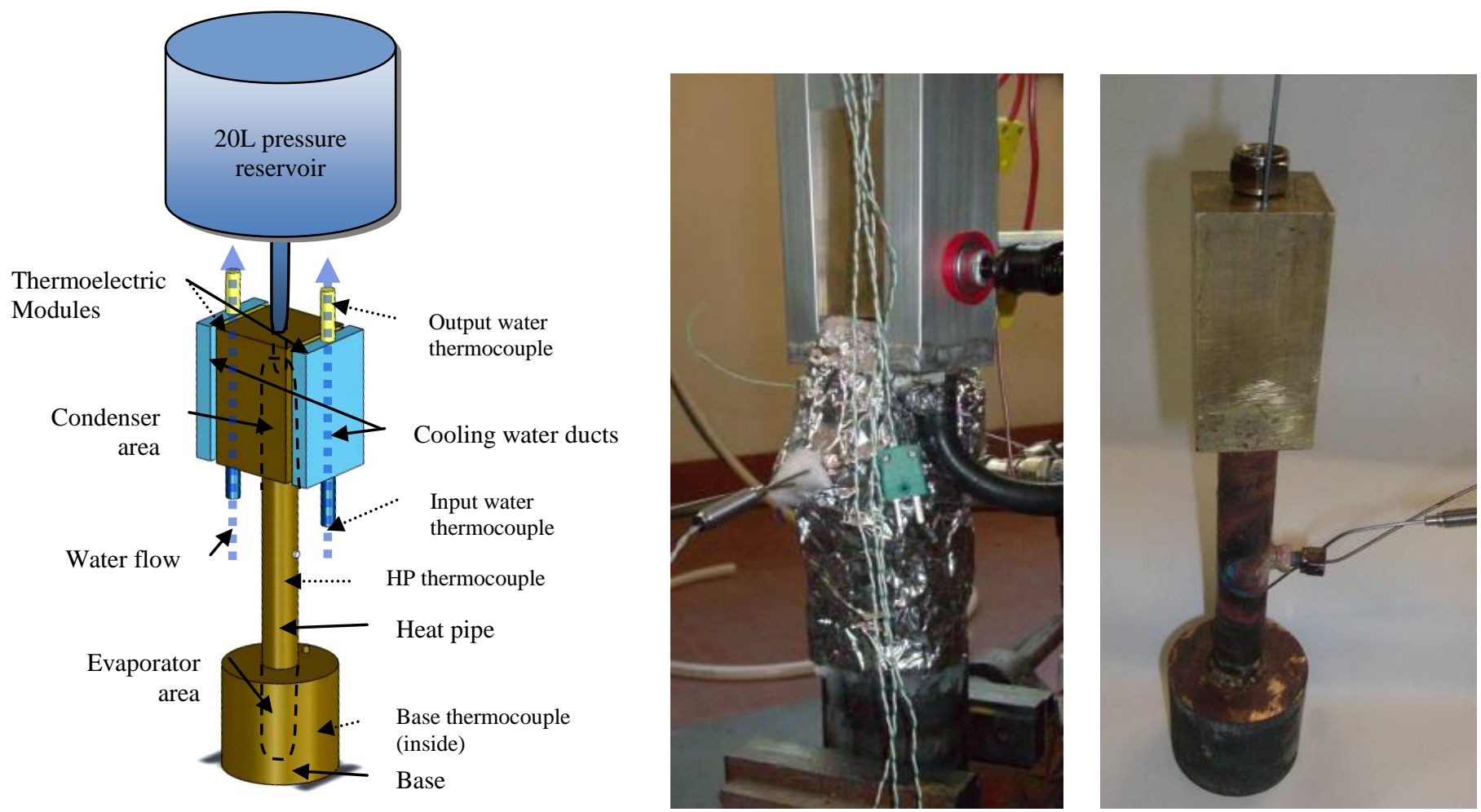

Figure 10 - (a) Outline and (b) photograph of Heat Pipe setup, with 20 L cylinder tank for VCHP operation and thermoelectric modules. (c) Detail of the bare HP without the tank nor the TEGs attached

\section{RESULTS}

\subsection{PRELIMINARY TESTS}

As noted above, the initial tests were done with the Heat Pipe displayed in Figure 7, simply placed over a thermal plate at $200^{\circ} \mathrm{C}$. In these tests the power never exceeded 180W, limited by the small heat transfer area (the interface between the hot plate and the lower tip of the Heat Pipe). As a consequence, a blow torch was used in order to increase the power supplied to the HP. Nevertheless, the restriction of the heat transfer caused by the small areas for vaporization and for condensation (restricted to the extremities of the HP, that is, their bottom and top surfaces) was too limitative to provide acceptable results.

\subsection{IMPROVED HP SETUP}

In order to overcome the limitation in heat transfer area mentioned above, another design, where the areas for vaporization and condensation inside the HP were much more extended, was consequently chosen (recall section 2.2). The power delivery was Page 9 of 19 
significantly improved to more than twice the previous values, with tests displaying heat transfer powers in excess of $300 \mathrm{~W}$ (Figure $11)$.

For these tests with the improved HP various quantities of water were used, either in the presence of air or in its absence. As predicted, for the tests where air was present (at atmospheric pressure) the heat transfer occurred only for temperatures above $100^{\circ} \mathrm{C}$, where full boiling would take place inside the HP (Figure 11a). Similar tests without air (Figure 11b) showed that the heat transfer was already possible with temperatures up from $40^{\circ} \mathrm{C}$, as the pressure inside the HP allowed for the water to boil at very low temperatures.

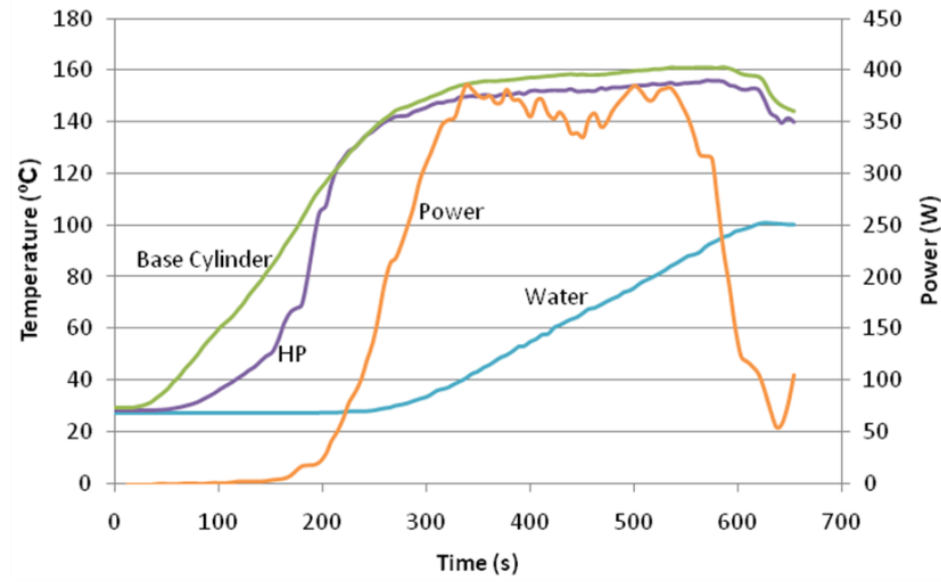

(a)

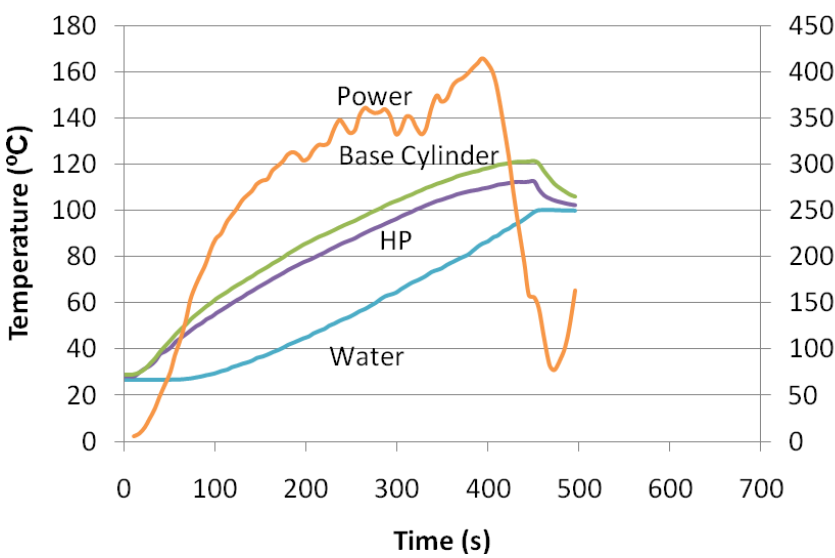

(b)

Figure 11 - HP with $10 \mathrm{~mL}$ of water (a) in the presence of air and (b) with no air (vacuum).

The amount of water inside the HP (5 mL, $10 \mathrm{~mL}$ and $20 \mathrm{~mL}$ ) did not seem to interfere with the results (Figure 12), as the main difference had to do with the onset of heat transfer.

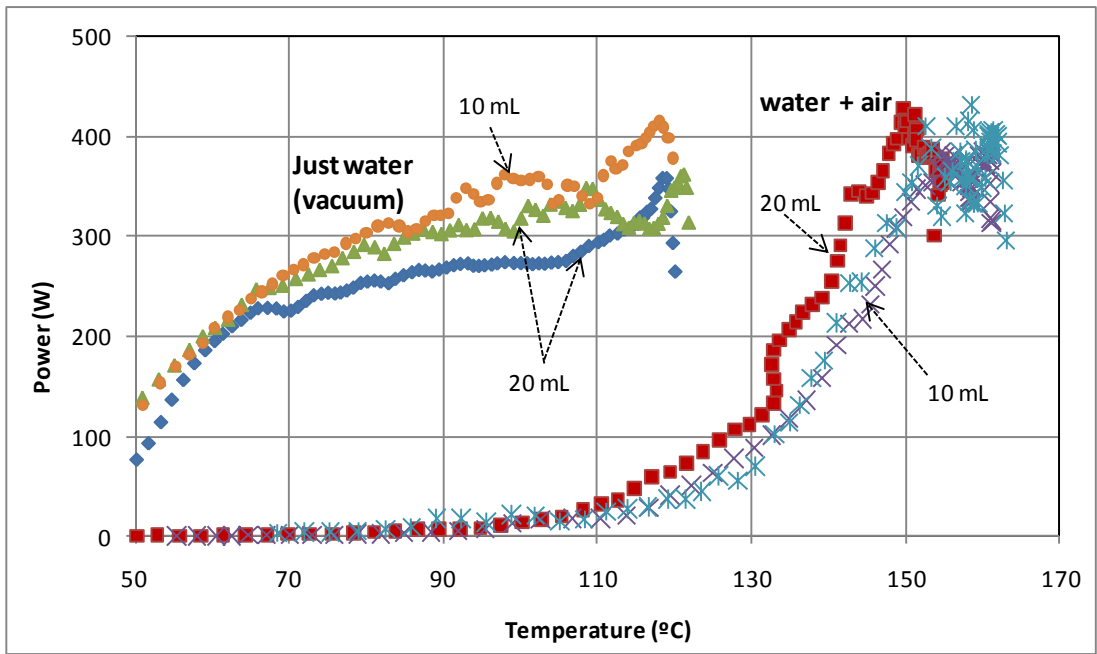

Figure 12 - Heat transfer across the HP as a function of base temperature. HP in vacuum and filled with air, respectively on the left and right graphs. Water volume of $10 \mathrm{~mL}$ and $20 \mathrm{~mL}$ in the evaporator of $\mathrm{HP}$.

Obviously, if more heat is supplied to the evaporator than the amount that could be removed through the condenser, the pressure inside the HP (along with temperature) would increase to dangerous levels. This could happen in situations where an HP would be used for harvesting the heat from a very hot exhaust manifold.

\section{Page 10 of 19}




\subsection{VARIABLE CONDUCTANCE HEAT PIPE TESTS}

With the valuable experience on the operation characteristics of standard Heat Pipes, it was decided to try to control the HP phase exchange temperature, by using the so-called Variable Conductance Heat Pipe (VCHP). For these tests the HP described previously was used, but the top of it was connected to a large $(20 \mathrm{~L})$ tank (recall Figure $8 \mathrm{~b}$ ), so that the pressure inside the HP could be specified and would not change during the HP operation. As explained above, this would enable the setting of a specified constant temperature for the heat pipe operation.

The first tests with the VCHP were very encouraging, as it was possible to further enhance heat transfer to values above 500W (see Figure 13). However, it was found that the heat transfer limitation was still on the side of the supply of heat to the vaporization zone. In fact, the temperature difference between the HP walls and the thermal fluid was rather small $\left(<5^{\circ} \mathrm{C}\right.$, see Figure 13$)$, indicating that more heat could be transferred across the evaporator.

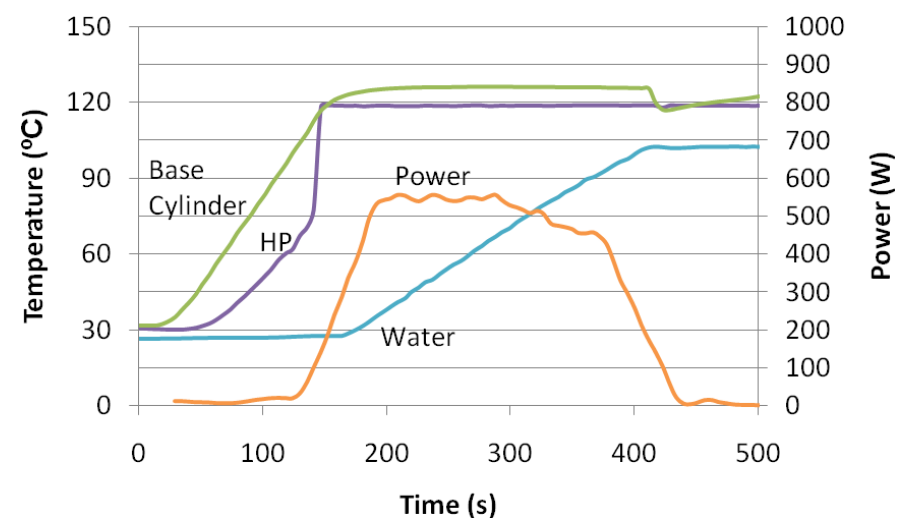

Figure 13 - VCHP with $20 \mathrm{~mL}$ of water and air at 2 bar

For the subsequent tests two blow torches were used (recall Figure 9), doubling the available power. For the lowest pressure of 1 bar absolute (atmospheric) it was possible to get a peak power exceeding $1 \mathrm{~kW}$, with a temperature difference between the wall and the fluid of about $20^{\circ} \mathrm{C}$ (Figure 14a). Increasing the pressure to $10 \mathrm{bar}$ (fluid temperature of $180^{\circ} \mathrm{C}$ ) the power was increased to more than $1.4 \mathrm{~kW}$ (Figure 14b), proving that these HP were capable of dealing with very large power inputs. These were good news, proving that these devices would be suitable for the ultimate objective of the present work: to find a safe and efficient way of transferring heat from the exhaust system of a vehicle to a cluster of thermoelectric modules.

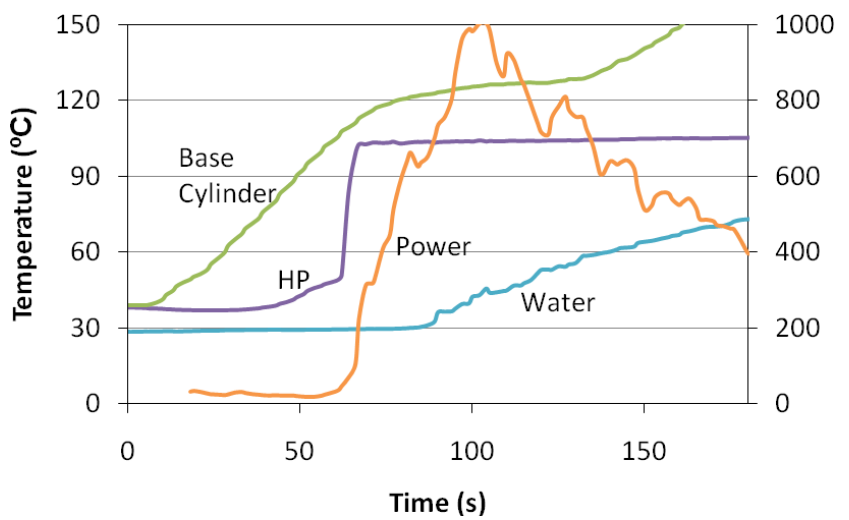

(a)

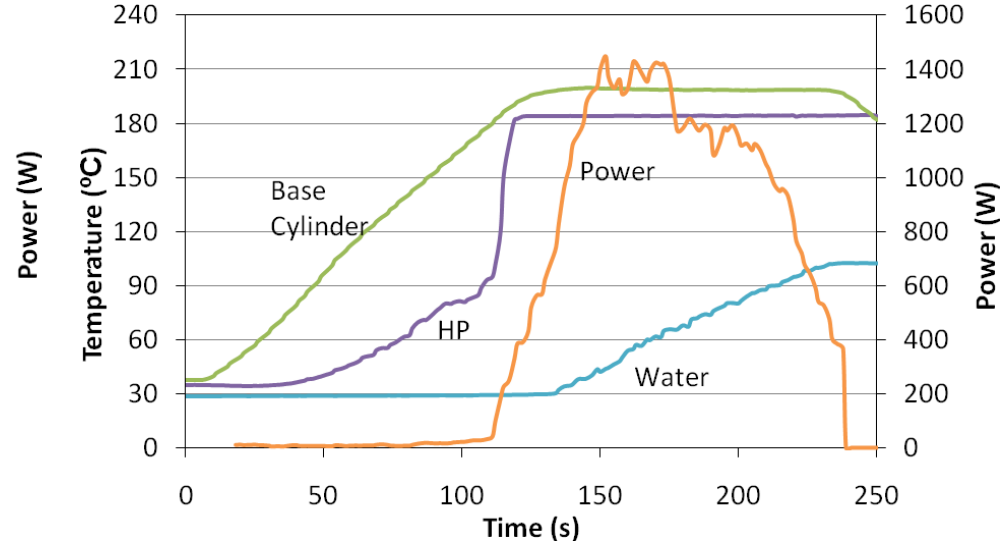

(b)

Figure 14 - VCHP with 2 blow torches: a) 1 bar; b) 10 bar

\section{Page 11 of 19}


Figure 15 displays the correlation between the recorded heat transfer rate and the corresponding operating temperature of the HP (which is connected to pressure). These values are all above $1 \mathrm{~kW}$. Although the maximum allowable operating temperature of the modules (around $230^{\circ} \mathrm{C}$ ) has not been achieved, it seems likely that the system's available heat transfer rate will be more than enough for the pretended application.

But before implementing a VCHP+TEG exhaust heat recovery prototype, additional tests were carried out, in order to evaluate the potential of the upper part of the HP, including heat removal and the use of the Seebeck modules.

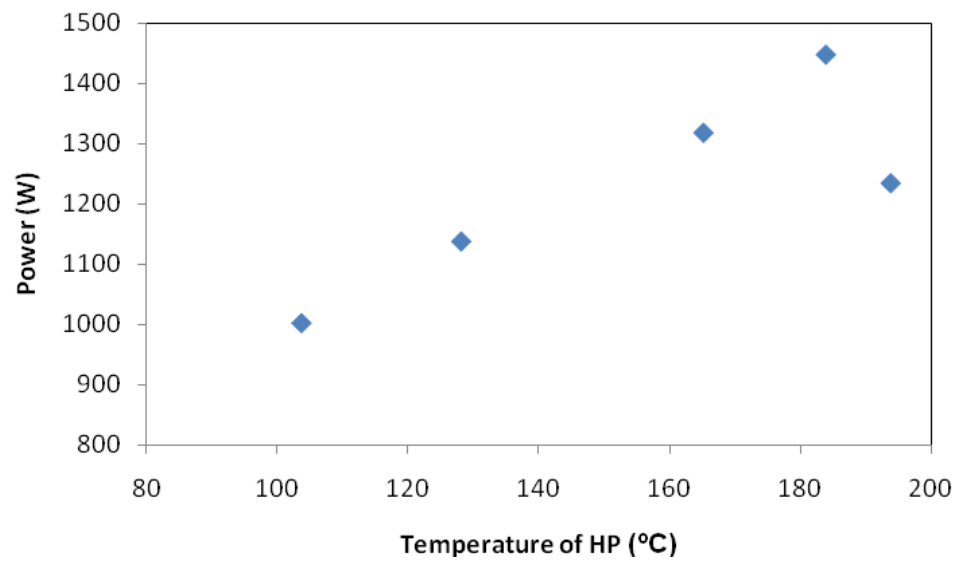

Figure 15 - Maximum transferred thermal power vs. HP temperature for VCHP

If the system would operate near the temperature limit of the Seebeck modules $\left(\sim 230^{\circ} \mathrm{C}\right)$ with water as the thermal fluid for the HP, a pressure of 23 bar (corresponding to the liquid-vapour equilibrium) would be required. As this is a very high pressure, the use of other fluids for the phase transition heat transfer in the heat pipes was tested. For some tests Dowtherm A was used, a fluid with a boiling temperature of $257^{\circ} \mathrm{C}$ at atmospheric pressure, falling to $220^{\circ} \mathrm{C}$ at $0.3 \mathrm{bar}$.

Initial tests with the standard HP (Figure 16) showed the lower heat transfer potential of Dowtherm A, when compared to water, as the heat transfer power was reduced to almost half of that obtained with water. Subsequent tests with the VCHP confirmed these results (Figure 17), with the power falling from $1400 \mathrm{~W}$ to less than $800 \mathrm{~W}$. However, this power range is still enough for the needs of the thermoelectric application under study.
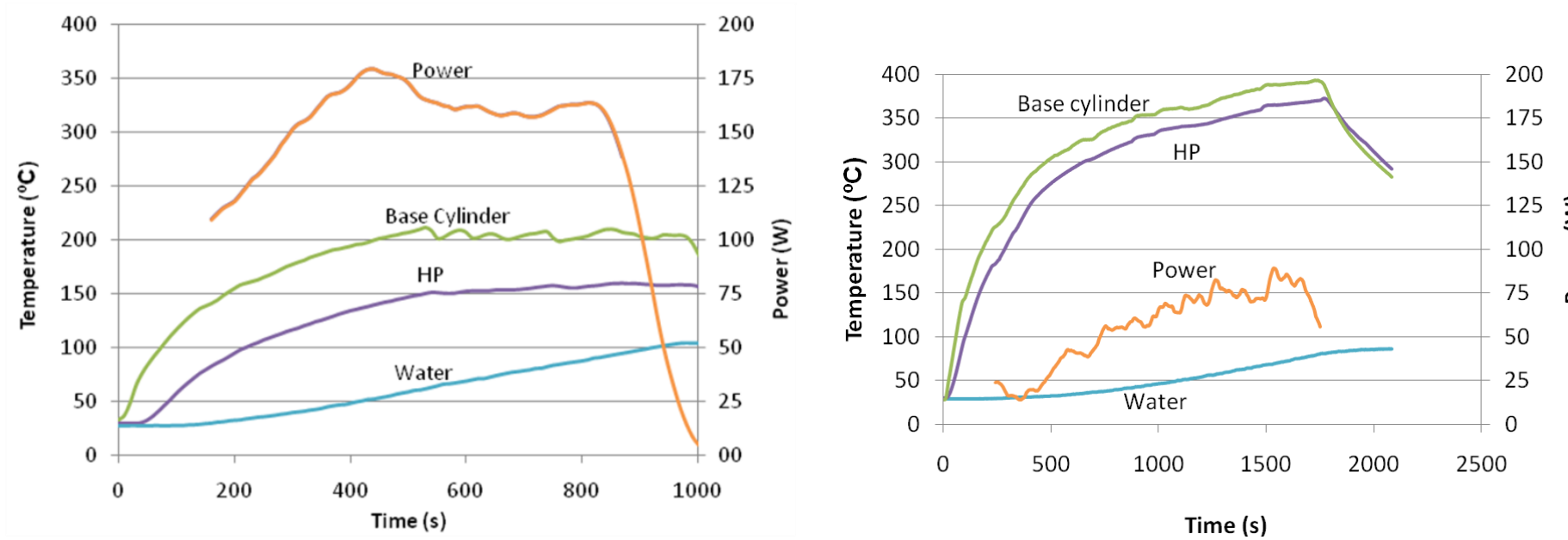

Page 12 of 19 
Figure 16 - Use of (a) water vs. (b) Dowtherm A

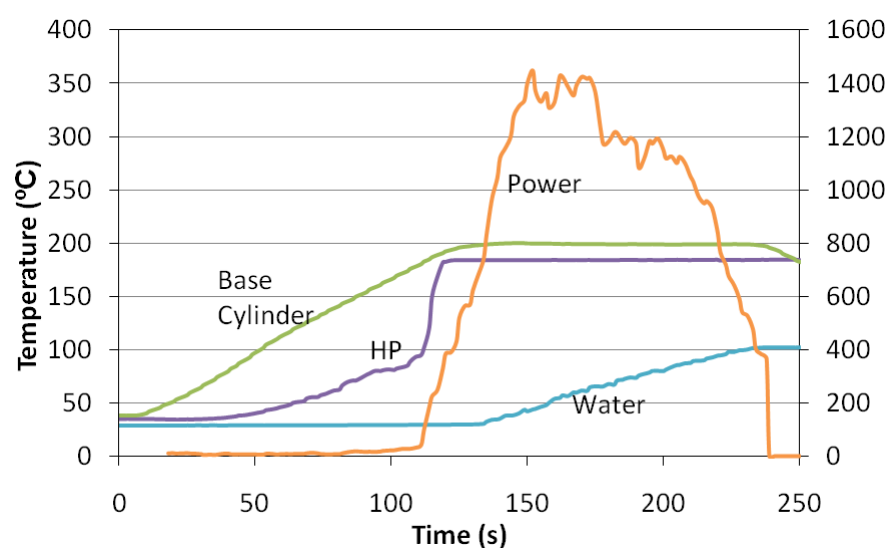

(a)

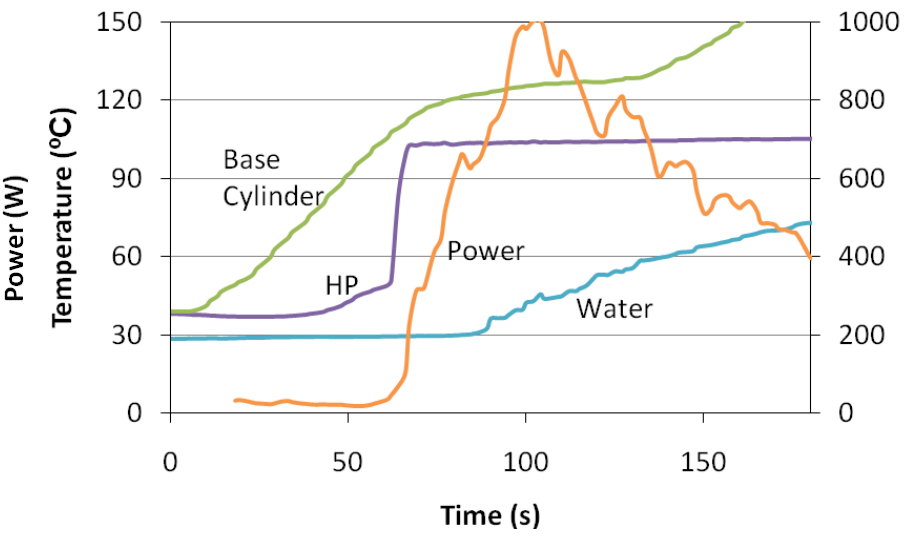

(b)

Figure 17 - Use of (a) water vs (b) Dowtherm A in a VCHP.

\subsection{SOLID TOP VCHP TESTS BEFORE TEG ATTACHMENT}

The last geometry tested (recall Figure 10) allowed the attachment of the TEG modules and water cooling ducts to their outer surfaces. Initial tests with this design were done for a constant flow rate of cooling water, without the modules, just to evaluate the potential of this design in terms of heat transfer at steady-state conditions, with the thermal power being removed by the cooling water (Figure $10 \mathrm{~b}$ ). Tests showed a heat retrieving potential of over $900 \mathrm{~W}$ at steady-state when two blow torches were used, and over $600 \mathrm{~W}$ when only one was in operation (Figure 18). 


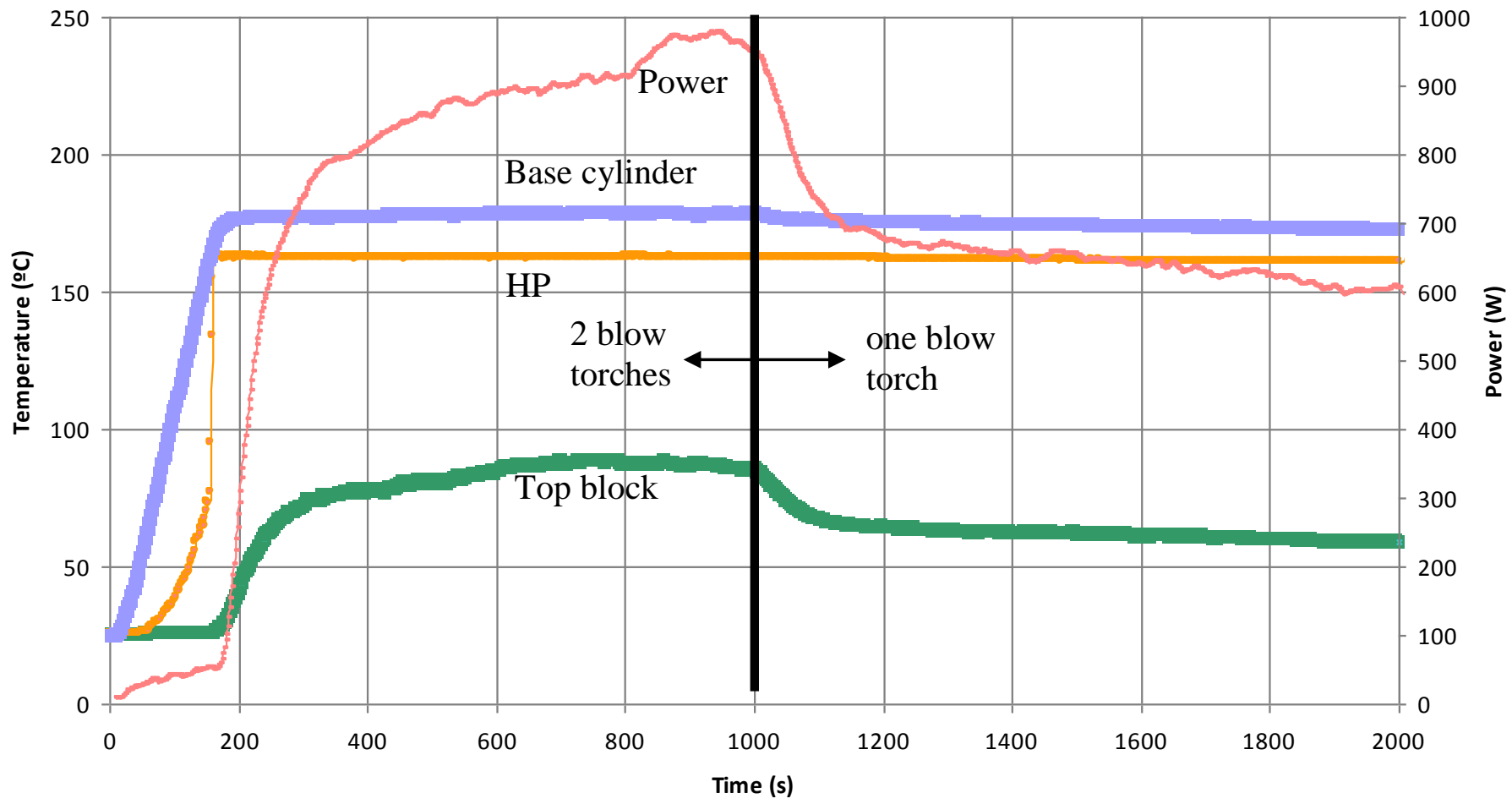

Figure 18 - Test of the VCHP for constant cooling flow rate (one/two blow torches)

\subsection{PRELIMINARY VCHP TESTS WITH 4 TEGs ATTACHED}

Finally, TEG modules were placed between the top block and the water cooling ducts. As only 4 modules were to be used, a low power setting (only one blow torch at part power) was used for these tests. The HP was operated with water at different pressures, corresponding to different temperatures at the top plate.

With the modules in place the power level was much lower (less than $300 \mathrm{~W}$ ), as a result of the lower power setting of the single blow torch and the added thermal resistance imposed by the modules. Figure 19 shows the power levels removed by the cooling water as a function of top block temperature (average water temperature of $25^{\circ} \mathrm{C}$ ). The temperature of the top block was only slightly lower than that of the HP.

Page 14 of 19 


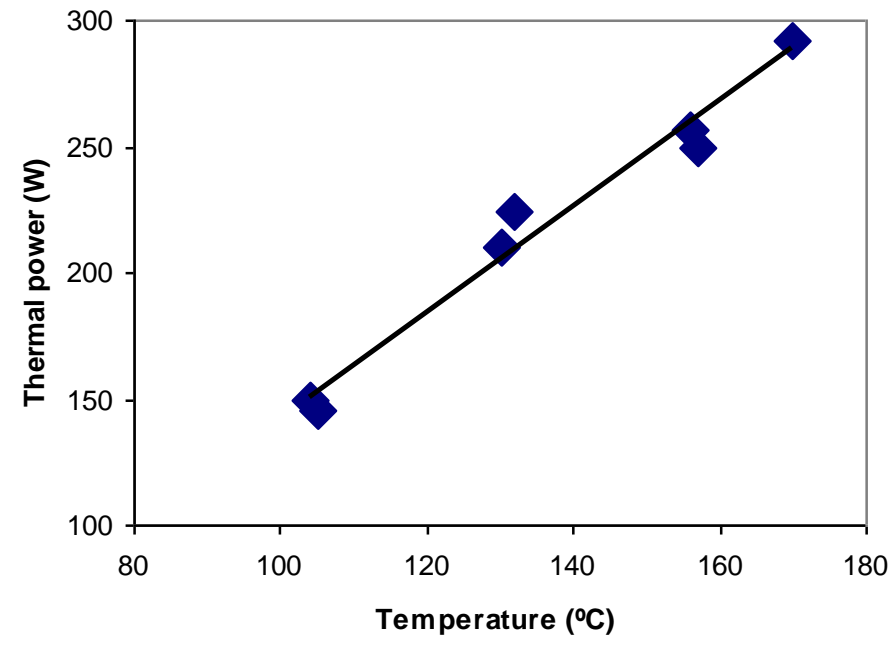

Figure 19 - Thermal power across the 4 modules.

The electric voltage and electric power generated by the 4 Seebeck modules, along with the efficiency of thermal energy recovery are plotted against the temperature difference between the top block and the cooling water in Figure 20.

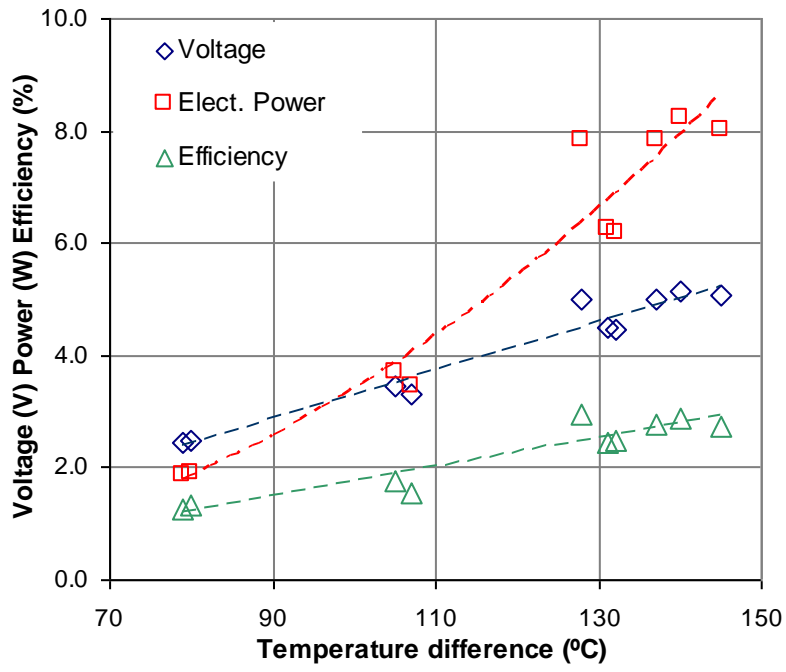

Figure 20 - Electric power, Voltage and Efficiency of the 4 modules as function of the temperature differential between the $\mathrm{HP}$ and the liquid cooling.

The trends are as expected (see Figure 4), with the data for electric power as a quadratic, and the curves for voltage and efficiency as nearly straight lines. The maximum efficiency (around 3\%) was obtained at the high $\Delta \mathrm{T}$ range for $\Delta \mathrm{T}=128^{\circ} \mathrm{C}$, corresponding to a top block temperature of $153^{\circ} \mathrm{C}$. For higher temperatures the efficiency remained at this level. This efficiency is still lower than expected (recall Figure 4). So is the maximum electric power generated $(8.2 \mathrm{~W})$ with 4 modules. Although no tests were performed with a temperature difference across the modules of more than $170{ }^{\circ} \mathrm{C}$, it is expected that both the power and the efficiency will keep increasing at the same rate, being expected that an efficiency around $4 \%$ can be obtained near the temperature limit of the modules.

Nonetheless, it should be noted that the real temperature difference across the modules should be smaller than the values presented in the plot. These actually represent the temperature differences between the HP temperature and the average cooling system temperature. In reality, the temperature differential across the TEGs (which has not been measured) is smaller because there is still the thermal resistance of the brass block and that corresponding to the convective heat transfer at the cooling system. Therefore, the recorded values of electric power, voltage and efficiency actually correspond to a lower temperature difference and so the real curves should be actually located further left in the plot and the performance of the modules is actually better than aprehended in Figure 20.

\section{Page 15 of 19}


Presently the group is modifying the installation in order to have this temperature information. A computer model is also under development in order to complement this analysis.

The actual electric output capacity of an automotive prototype based on the solutions proposed in this work will depend on the exhaust heat retrieving capacity of the system and on its size (namely the number of modules). If, in the limit, all exhaust heat would be channelled through the system and there would be sufficient modules, a maximum of $4 \%$ of the exhaust heat would be recovered into electricity. Taking into account that the heat released by the exhaust of the engine is roughly the same as its mechanical work, in the limit, an improvement in vehicle efficiency of around $4 \%$ could be achieved. Of course, it is not possible to channel all the exhaust heat towards the TEG system and therefore this efficiency will actually be lower. Also, a huge amount of modules would be necessary to gather all the available energy potential. Nevertheless, the present work has illustrated a heat retrieving method with a good heat retrieving potential and still with room for improvement. As TEG technology improves over time and fuel prices rise, the use of these technologies in automotive applications will eventually gain attractiveness.

\subsection{IMPROVEMENT POTENTIAL, FUTURE WORK}

The results presented are still preliminary as the system is still in a relatively early stage of development and therefore the limits for electric power output and efficiency of the modules can still be further extended. This can be achieved by employing several concurrent strategies that will be carried out by the group in the near future, some of them being already under development such as tuning the operating temperature to the optimum value that is, increasing the operating temperature up to the maximum value that the TEGs can safely withstand. This can be done by using water at higher pressures or by using a different fluid, such as the Dowtherm A that has been already used for some tests. Another strategy will be to increase the temperature difference across the modules by improving the cooling of the outer TEG surface and by reducing the thermal resistance of the set. Also, the lower part of the HP will be finned and immersed in a pipe with hot gas flow, in order to more accurately resemble an actual automotive exhaust system. Naturally, since TEG technology is constantly evolving, the use of more efficient TEG modules with less thermal resistance, higher ZT and higher operating temperature limit should be favoured as soon as they are available.

The commercial success of a Thermoelectric system prototype for automotive applications such as the one under development will heavily depend on the ability to find a design that not only is energy efficient but is also compact and light. Further work on the optimization of the HP geometry, the number of modules per HP and the packaging of the system will have further development. The connection of the TEG-VCHP apparatus to an actual exhaust system of an ICE car has still to be implemented.

\section{CONCLUSIONS}

An extensive study was carried out to assess the potential of the combined use of Heat Pipes and commercially available thermoelectric modules for energy recovery of waste heat from the exhaust gases of automotive IC engines. The heat pipes were used as a means of efficiently transferring the heat from the hot exhaust gases to the TEGs at a temperature level that does not damage the TEGs, which are temperature limited. Several successive HP designs were tested with a clear improvement of the latter designs over the initial ones, both in terms of temperature and pressure control as well as heat transfer rate. Namely, it was possible to achieve a control over the pressure and temperature of the HP under operation, while the heat transfer rate channelled through the HP also improved significantly, sometimes exceeding $1.4 \mathrm{~kW}$.

One of the limitations of these commercial modules is that they display a maximum allowable temperature which is much lower than the typical temperature level of the exhaust gases. A new HP design was developed so that its working temperature could be controlled. This was achieved by using the so-called Variable Conductance Heat Pipe (VCHP) design in which a large tank with adjustable pressure is connected to the HP.

Two different fluids were used, water and Dowtherm A. The latter showed a significant lower potential for HP use, with power levels reduced to less than half of those achievable with water. However, Dowtherm A works at a lower pressure when compared with water, thus recommended mainly for working temperature above $200^{\circ} \mathrm{C}$, where the high water pressure would otherwise require a special design. The VCHP design demonstrated the ability to control the working temperature of modules and keep it below the maximum allowable limit. The operating temperature of the HP was successfully controlled through the regulation of the pressure inside of the HP. The values ranged from $100^{\circ} \mathrm{C}$ to near $200^{\circ} \mathrm{C}$, with pressures varying between $1 \mathrm{bar}$ and $13.5 \mathrm{bar}$.

Page 16 of 19 
The last design, which is still under early development, included the preliminary evaluation of the potential for the combined use of HP and thermoelectric modules to produce electricity. Values of 3\% efficiency (calculated based on the heat removed from the Heat Pipe through the cooling system) were recorded for temperature differences of $130^{\circ} \mathrm{C}$ across the $\mathrm{HP}$ and the water cooling system (the actual temperature difference across the modules will be somewhat lower). While a linear increase of voltage and efficiency with temperature was observed, a second order increase was recorded in the electric power. This pilot solution, which has still a good potential for improvement, can be scalable (only four modules were used in the present work) and opens the door for a viable thermoelectric generator for exhaust gas systems, enabling some heat recovery from the engines of standard vehicles, Hybrids and Extended Range Electric Vehicles.

\section{REFERENCES}

1. Jost, K. "Upfront (Editorial): Green Innovations", Automotive Engineering International, 118-3, p. 4. 2010

2. Tate, E. D., Harpster, M. O., Savagian, P. J., "The Electrification of the Automobile: From the Conventional Hybrid, to Plug-in Hybrids, to Extended Range Electric Vehicles", SAE 2008-01-0458, 2008.

3. Ribeiro B., Brito F.P., Martins J., "A Survey on Electric/hybrid Vehicles", Transmission and Driveline 2010 (SP-2291), SAE International Publ., ISBN 978-0-7680-3425-7, pp. 133-146, 2010.

4. Martins L.A.S.B, Brito J.M.O., Rocha A.M.D. and Martins J.J.G., "Regenerative Braking Potential and Energy Simulations for a Plug-in Hybrid Electric Vehicle under Real Driving Conditions", Proceedings of IMECE09: 2009 ASME International Mechanical Engineering Congress and Exposition, November 13-19, 2009, Lake Buena Vista, Florida, USA, 2009

5. Martins J., "Motores de Combustão Interna", 2nd edition, Publindustria, Portugal, 2006

6. Heywood J., Internal Combustion Engine Fundamentals, McGraw Hill, 1988.

7. Kutlar O.A., Arslan H. and Calik A.T., "Methods to Improve Efficiency of Four Stroke, Spark Ignition Engines at Part Load", Energy Conversion and Management, Elsevier, 46, pp. 3202-3220, 2005

8. Martins J. J.G., Uzuneanu K., Ribeiro B. and Jasansky O., "Thermodynamic Analysis of an Over-Expanded Engine", SAE Technical Paper Series, $n^{\circ}$ 2004-01-0617, included in 'Modeling of Spark Ignition Engines', edited by SAE (ISBN Number: 07680-1366-6), 2004.

9. Gonçalves L.M., Martins J., Antunes J., Rocha R. and, Brito F. P.’Heat-Pipe Assisted Thermoelectric Generators for Exhaust Gas Applications”, ASME 2010 International Mechanical Engineering Congress \& Exposition, November, 12-18, 2010, Vancouver, British Columbia, Canada, 2010.

10. Ashley, S. "SMA-based Energy Scavenging Device Could Convert Exhaust Heat Into Useful Power", Automotive Engineering International, 118-3, pp. 16-19, 2010.

11. Rowe, D. M. (editor). Handbook of thermoelectrics. CRC Press, 1987

12. Short, J.L., D’Angelo J., Downey A.D., Pajor M.A., Timm E., Schock H., Kanatzidis M.G. and Hogan T. P., "Characterization of Thermoelectric Power Generation Modules Made from New Materials", Mater. Res. Soc. Symp. Proc. Vol. 886, Materials Research Society, , 2006.

13. Hogan T.P. et al, "Nanostructured Thermoelectric Materials and High-Efficiency Power-Generation Modules", Journal of Electronic Materials, Vol. 36, No. 7, 2007

14. Neild Jr. A.B. "Portable thermoelectric generators", Society of Automotive Engineers, New York, SAE-645A, 1963.

15. Birkholz, U., Grob, U. Stohrer and K. Voss, "Conversion of Waste Exhaust Heat in Automobile using FeSi2 Thermoelements". Proc. 7th International Conference on Thermoelectric Energy Conversion. 1988, Arlington, USA, pp. 124-128, 1988

16. Bass J. C., Elsner N. B. and Leavitt F. A. "Performance of the $1 \mathrm{~kW}$ Thermoelectric Generator for Diesel Engines" International Conference on Thermoelectrics, 1994, Kansas City, Kansas, USA, 1994.

17. Kushch A., Karri M. A., Helenbrook B. T. and Richter Clayton J., "The Effects of an Exhaust Thermoelectric Generator of a GM Sierra Pickup Truck." Proceedings of Diesel Engine Emission Reduction (DEER) conference, 2004, Coronado, California, USA, 2004

18. LaGrandeur J., Crane D., Eder A., "Vehicle Fuel Economy Improvement through Thermoelectric Waste Heat Recovery", DEER Conference, 2005, Chicago, IL, USA, 2005

19. LaGrandeur J., Crane D, Hung S., Mazar B. and Eder A., "Automotive waste heat conversion to electric power using skutterudite, TAGS, PbTe and BiTe", International conference on thermoelectric, p. 343-48, 2006

20. Thacher E. F., Helenbrook B. T., Karri M. A., and Richter Clayton J. "Testing an automobile thermoelectric exhaust based thermoelectric generator in a light truck" Proceedings of the I MECH E Part D Journal of Automobile Engineering, 221-1, pp. 95107(13), 2007. 
21. Stobart R.K., Wijewardane A. and Allen C., "The Potential for Thermo-electric Devices in Passenger Car Applications", Advanced Hybrid Vehicle Powertrains, 2010 (SP-2275), paper n.2010-01-0833, SAE International, 2010.

22. L. Bell, "Cooling, heating, generating power, and recovering waste heat with thermoelectric systems", Science, 321, pp. 1457$1461,2008$.

23. Min Gao and Rowe D. M., " Conversion Efficiency of Thermoelectric Combustion Systems " IEEE Transactions on Energy Conversion, 22- 2, June, 2007,

24. Whitworth, B., "BMW reveals plans for Efficient Dynamics Mk2 - interview with BMW's head of development Klaus Draeger ", in car Magazine, March 2009. link: http://www.carmagazine.co.uk/News/Search-Results/Industry-News/BMW-reveals-plans-forEfficient-Dynamics-Mk2/

25. Matsubara K., "Development of a high efficient thermoelectric stack for a waste exhaust heat recovery of vehicles", International conference on thermoelectric, p. 418-23, 2002.

26. Goldsmid H. J., "CRC Handbook of Thermoelectrics", London CRC Press, edited by D.M. Rowe, 1987.

27. Yunus A. Çengel, "Heat Transfer - A practical approach", McGraw-Hill, p. 364, 1998.

28. Reay D., Kew P. "Heat Pipes: Theory, Design and Applications", BH, 2006.

29. Incropera F.P. and deWitt D.P., "Fundamentals of Heat and Mass Transfer", $3^{\text {rd }}$ Ed., Wiley, 1990.

\section{CONTACT INFORMATION}

Jorge Martins is an Associate Professor at the Mechanical Engineering Department of the Universidade do Minho at Guimaraes, Portugal, where he is head of the I.C. Engines Laboratory. He can be contacted at jmartins@dem.uminho.pt

Francisco P. Brito is a Post-Doctoral researcher at the Universidade do Minho at Guimaraes, Portugal. He can be contacted at francisco@dem.uminho.pt

Luís Gonçalves is an Auxiliar Professor at the Industrial Electronics Department of the Universidade do Minho at Guimaraes, Portugal. He can be contacted at lgoncalves@ dei.uminho.pt

\section{ACKNOWLEDGMENTS}

Francisco Brito thanks the FCT and the MIT Portugal Program for the financial support given for his research activities (SFRH / BPD / 51048 / 2010).

This research project was supported by MIT-Pt/EDAM-SMS/0030/2008.

\section{DEFINITIONS/ABBREVIATIONS}

BEV Battery Electric Vehicle

EREV Extended Range Electric Vehicle

EV Electric Vehicle

HEV Hybrid Electric Vehicle

HP Heat Pipe

ICE Internal Combustion Engine

OEM Original Equipment Manufacturer

SI Spark Ignition

TEG Thermoelectric Generator

Page 18 of 19 
Figure-of-merit of a thermoelectric module

Page 19 of 19 